\title{
Ulcerative pyoderma gangrenosum
}

\author{
Megan Sander DMD, Michael Sander MD
}

— Cite as: CMAJ 2019 September 23;191:E1058. doi: 10.1503/cmaj.190721

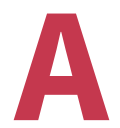

59-year-old woman with systemic lupus erythematosus presented with a 1-month history of an enlarging, exquisitely painful ulcer on her left calf (Figure 1). She reported that it had occurred secondary to a spider bite; however, the spider had not been seen. She had been assessed by a surgeon, who, suspecting an infection, débrided the wound. However, thereafter, the ulcer enlarged more rapidly. Physical examination showed a deep ulcer $(8 \times 7 \mathrm{~cm})$, with grey, undermined borders and a necrotic base. Pyoderma gangrenosum was suspected and was ultimately confirmed after 2 biopsies were performed to rule out alternative diagnoses.

Ulcerative pyoderma gangrenosum is a rare inflammatory disease with an incidence of 3-10 cases per million per year. ${ }^{1}$ Consideration of the diagnosis is based on its classic morphological features: ulcers have a purulent base and an overhanging gunmetal grey border. ${ }^{2}$ However, it is a diagnosis of exclusion, and histological investigations are used to rule out other causes. ${ }^{3}$ If pyoderma gangrenosum is suspected, 2 punch biopsy specimens should be collected from the ulcer's edge, 1 for pathological examination, and 1 for culture of bacteria, atypical mycobacteria and deep fungi. ${ }^{3}$ Because roughly $50 \%$ of cases are associated with systemic disease, most commonly inflammatory bowel disease, arthritis and hematologic disease, ${ }^{3}$ an underlying systemic disease should be sought. Treatment is with immunosuppressive agents, and reepithelialization occurs gradually from the periphery of the wound, and the wound heals with an atrophic, cribriform scar. ${ }^{2}$ Our patient's ulcer began to heal with cyclosporine treatment.

We note the common history of an insect bite; however, the bite is unwitnessed and the culprit never seen. We encourage physicians not to be dissuaded from the diagnosis of pyoderma gangrenosum based on this red herring. Since pyoderma gangrenosum is prone to worsening after trauma (pathergy), it is important not to débride the lesion. ${ }^{1}$

\section{References}

1. Monari P, Moro R, Motolese A, et al. Epidemiology of pyoderma gangrenosum: results from an Italian prospective multicentre study. Int Wound J 2018;15: 875-9.

2. Miller J, Yentzer B, Clark A, et al. Pyoderma gangrenosum: a review and update on new therapies. J Am Acad Dermatol 2010;62:646-54.

3. Ruocco E, Sangiuliano S, Gravina A, et al. Pyoderma gangrenosum: an updated review. J Eur Acad Dermatol Venereol 2009;23:1008-17.

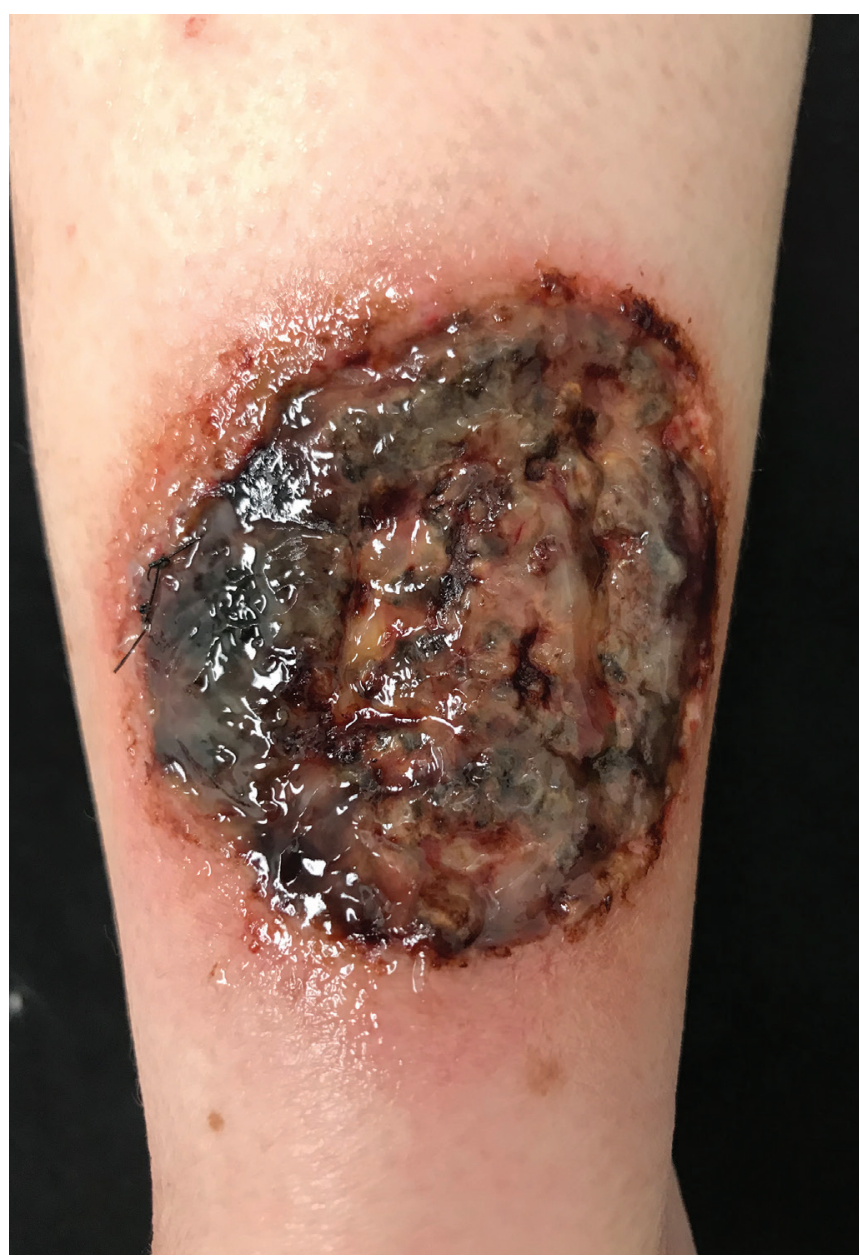

Figure 1: A large ulcer $(8 \times 7 \mathrm{~cm})$ with grey, undermined borders and a purulent base on the calf of a 59-year-old woman with systemic lupus erythematosus.

\section{Competing interests: None declared.}

This article has been peer reviewed.

The authors have obtained patient consent.

Affiliations: Department of Medicine (Megan Sander) and Cumming School of Medicine (Michael Sander), University of Calgary, Calgary, Alta.

Correspondence to: Megan Sander, megan.a.sander@gmail.com 